Sharif University of Technology
Scientia Iranica
SCIENTIA
I RAN I CA

\title{
Investigating the seismic behavior of RC shear walls with openings strengthened with FRP sheets using different schemes
}

\author{
B. Mohammadi Vojdan and R. Aghayari* \\ Department of Civil Engineering, Razi University, Kermanshah, Iran. \\ Received 7 January 2016; received in revised form 8 April 2016; accepted 24 May 2016
}

\author{
KEYWORDS \\ RC shear wall; \\ Strengthening; \\ FRP; \\ Opening; \\ Finite element.
}

\begin{abstract}
This paper investigates the seismic behavior of RC shear walls strengthened by Fiber Reinforced Polymer (FRP) composites. In this research, the effects of strengthening shear walls with different strengthening schemes and also strengthening walls with openings in different dimensions and locations are studied. The development of nonlinear finiteelement methods has improved the accuracy of seismic analysis of complex structures. In this study, the ABAQUS software is used to investigate the final resisting parameters, ductility, and behavior factor in these walls using nonlinear static analysis. The findings prove that the applied strengthening schemes increase the final strength of the wall. Also, the increasing ductility, behavior factor, and increased overstrength factor in some of these walls compared with original walls are observed. The findings also prove that special openings with limited dimensions to improve seismic behavior of the wall are effective, and the only limitation of using these openings is decreasing the final strength which can be made up by using a proper strengthening scheme of FRP.
\end{abstract}

(C) 2017 Sharif University of Technology. All rights reserved.

\section{Introduction}

In many existing RC buildings, shear walls constitute the seismic force-resisting system. Due to their high initial stiffness and lateral load capacity, they are an ideal choice for a lateral load-resisting system in an RC structure. They must provide not only adequate strength, but also sufficient ductility to avoid brittle failure under strong lateral loads, especially during an earthquake. However, a large inventory of existing structures was designed and built according to earlier seismic codes, which do not meet the current design standards. Such structures possess a number of structural deficiencies including inadequate shear capacity, insufficient confinement reinforcement, inade-

*. Corresponding author.

E-mail addresses: b.mohammadivojdan@gmail.com (B. Mohammadi Vojdan); reza_agh@razi.ac.ir (R. Aghayari) quate stiffness, and having openings for windows, doors and duct spaces for functional reasons whose number, location, and size of the openings affect the behavior of the structure. Therefore, there is an essential need for investigating the effective means of strengthening the existing RC shear walls to upgrade the seismic performance of these walls, such that they can meet recent requirements of the design codes.

Several techniques are available for strengthening or retrofitting $\mathrm{RC}$ structures. These techniques use different materials, such as steel, concrete, and shape memory alloys, used in different methods of application [1-5]. FRP composite materials are proper methods for increasing capacity of the wall regarding the conceptions of capacity and ductility. In recent years, FRP composites have been broadly and successfully used to improve seismic behaviors of the structures in the form of FRP laminates, sheets, or rods. FRP sheets can be bonded to the wall surface by using epoxy 
resin and anchored to the wall foundation by using steel or FRP anchors. The use of FRP composites for the purpose of retrofitting $\mathrm{RC}$ shear walls was investigated through an early experimental and analytical program by Lombard et al. [6]; they increased the flexural capacity, stiffness, and the shear capacity of the shear wall by using one-horizontal layer of FRP (CFRP) sheet between two vertical layers of FRP. Antonides et al. [7] used FRP strips at the wall edges along with FRP jackets to strengthen repaired RC walls to enhance both flexural and shear capacities. Khalil \& Ghobarah [8] used a rehabilitation scheme to improve the strength by using two wrapping layers of biaxial FRP woven at $\pm 45^{\circ}$ and ductility by using U-shaped partial hoops of CFRP uni-directional sheets wrapped around the edge element. El-Sokkary et al. [9] studied the effects of rehabilitation of two 8-story cantilevered RC shear walls by CFRP laminates through a shake table test program consisting of testing the walls under several levels of ground motion excitation. Four different strengthening schemes had been used to increase the flexural strength; the walls represented the 6th story of an eight-story RC shear wall. The tested walls had been strengthened by using vertical FRP stirrup at top or bottom of wall, one horizontal layer of CFRP at the bottom of wall and the horizontal FRP wrap. ElSokkary and Galal [10] applied X-FRP bracing to the two sides of the wall, and the strengthened wall showed satisfactory performance with improved flexural and shear strength under cyclic loading. However, limited experimental studies have been conducted to investigate the performance of structural walls retrofitted by wrapping FRP strips or sheets, especially on structural walls with openings in a series of experimental studies carried out by Li et al. [11]. They studied the effectiveness of repair and strengthening schemes of using FRP strips in recovering the seismic performance of the walls with irregular or regular openings. The repaired walls managed to recover their strength, dissipated energy, and stiffness reasonably.

Typically, the seismic performance of a retrofitted RC shear wall is evaluated experimentally through assessing its hysteretic lateral force displacement relationships. Although experimental testing is seen to be the most evident approach to assess the performance of a shear wall, numerical simulations would provide valuable tools for parametric studies and assessments of the seismic response of RC shear walls. This study investigates the details of numerical modeling of $\mathrm{RC}$ shear walls strengthened with FRP using FiniteElement (FE) method. The developments in nonlinear finite-element methods have provided the conditions to perform reliable analysis. In this study, the effectiveness of different FRP strengthening schemes in walls' performance is presented, and the goal is to investigate whether the walls with openings could restore their seismic performance after the proposed strengthening schemes.

The study is divided into two phases. The objectives in phase one are to investigate different schemes of the FRP strengthening systems and their effectiveness in characteristics such as strength, ductility, energy dissipation, and stiffness using Pushover analysis. In phase two, similar walls with openings are modeled, and location and size of the openings are different. In order for the walls to restore their seismic performance, different FRP strengthening schemes are presented and the characteristics of the walls are investigated.

\section{Analysis method}

Nonlinear static analysis (Pushover analysis) was used in this study to evaluate the global limit states of the $\mathrm{RC}$ shear walls in terms of drift and force levels. In this analysis, the increasing forcing function is imposed on a mathematical model of a shear wall in terms of displacements. The analysis is terminated when the target displacement or ultimate limit state is reached. The target displacement or drift represents a maximum displacement or drift during an earthquake shaking. This kind of analysis can estimate the maximum strength and deformation capacity of the shear wall. Nonlinear static analysis is used to find the global limit states with loading profile of the first mode shape.

\section{Response modification factor}

The concept of response modification factor, commonly known as force reduction factor, has emerged as a single most important number, reflecting the capability of the structure to dissipate energy through inelastic behavior. This factor is unique and different for different types of structure and material used. Hence, classification of response modification factor for various structural systems is extremely important in order to perform an evaluation based on demand (earthquake ground motion) and capacity of the structure. $R$ factors are essential seismic design tools, which define the level of inelasticity expected in structural systems during an earthquake event. $R$ factor reflects the capability of structure to dissipate energy through inelastic behavior. $R$ factor is used to reduce the design forces in an earthquake-resistant design and accounts for damping, energy dissipation, capacity and for overstrength of the structure. The philosophy of an earthquake-resistant design is that a structure should resist earthquake ground motion without collapse, but with some damage. Consistent with this philosophy, the structure is designed for much less base shear forces than required if the building is to remain elastic during severe shaking at a site. Such large reductions are mainly due to two factors: (1) ductility reduction factor 


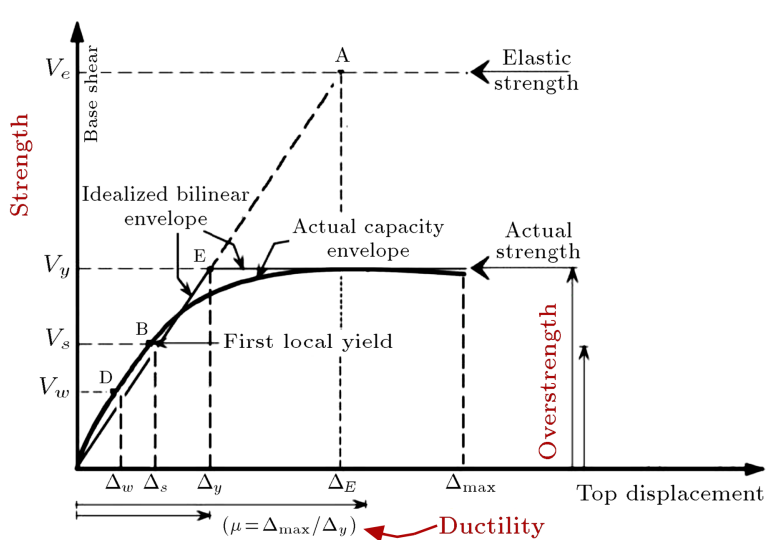

Figure 1. Relationship between force reduction factor $(R)$, structural overstrength $\left(R_{\Omega}\right)$, and ductility reduction factor $\left(R_{\mu}\right)$.

$R_{\mu}$ which reduces the elastic demand force to the level of the maximum yield strength of the structure; (2) overstrength factor $\left(R_{\Omega}\right)$ which accounts for the overstrength introduced in code-designed structures. Thus, response reduction factor $(R)$ is simply calculated as follows, see Figure 1:

$$
R=R_{\mu} \times R_{\Omega}
$$

\subsection{Ductility reduction factor $\left(R_{\mu}\right)$}

Ductility reduction factor $\left(R_{\mu}\right)$ is a factor which reduces the elastic force demand to the level of idealized yield strength of the structure; hence, it may be represented as in the following equation:

$$
R_{\mu}=\frac{V_{e}}{V_{y}}
$$

$V_{e}$ is the max base shear coefficient if the structure remains elastic. Ductility reduction factor $\left(R_{\mu}\right)$ takes advantage of the energy dissipating capacity of properly designed and well-detailed structures; hence, it primarily depends on the global ductility demand, $\mu$, of the structure ( $\mu$ is the ratio between the maximum roof displacement and yield roof displacement). Newmark and Hall [12] made the first attempt to relate $\left(R_{\mu}\right)$ with $\mu$ for a Single-Degree-Of-Freedom (SDOF) system with Elastic-Perfectly Plastic (EPP) resistance curve. By having extensive analysis and study of elastic and inelastic spectra, three regions of response, dependent on the period of the structure, were identified by Newmark and Hall [13], which are as follows:

Short period:

$$
T<0.2 \mathrm{sec} \quad P_{d}=P_{e}
$$

Intermediate period:

$$
0.2<T<0.5 \mathrm{sec} \quad P_{d}=\frac{P_{e}}{\sqrt{2 \mu-1}}
$$

Long period:

$$
T>0.5 \mathrm{sec} \quad P_{d}=\frac{P_{e}}{\mu},
$$

where $P_{d}$ is designing force; $P_{e}$ is elastic force; $\mu$ is ductility; and $T$ is dominant vibration period.

\subsection{Structural overstrength $\left(R_{\Omega}\right)$}

Structural overstrength plays an important role in collapse prevention of the buildings. Overstrength factor $\left(R_{\Omega}\right)$ may be defined as the ratio of actual to the design lateral strength:

$$
R_{\Omega}=\frac{V_{y}}{V_{s}},
$$

where $V_{y}$ is the base shear coefficient corresponding to the actual yielding of the structure; and $V_{s}$ is the codeprescribed unfactored design base shear coefficient.

To design allowable stress method, the design codes decrease design loads from $V_{s}$ to $V_{w}$. This decrease is done by allowable stress factor defined as follows:

$$
Y=\frac{V_{s}}{V_{w}}
$$

\section{Finite-element model}

In this study, nonlinear analysis was utilized using the finite-element analysis software ABAQUS. The concrete wall was modeled using C3D8R elements. Reinforcement bars are modeled in the form of two dimensional truss elements (T3D2) embedded in C3D8R solid elements. External FRP is modeled using S4R elements with orthotropic behavior. The boundary condition at the base of the wall is simulated as fixed end.

\subsection{Material properties}

Reinforced concrete is a complicated material to model. Among three crack models for reinforced concrete elements which ABAQUS software provides [14], i.e., (1) smeared crack concrete model, (2) brittle crack concrete model, and (3) Concrete Damaged Plasticity model (CDP), CPD model is used in order to model the complete inelastic behavior of concrete in both tension and compression, including damage characteristics. This model assumes that the main two failure mechanisms of concrete are tensile cracking and compressive crushing. In this model, uniaxial tensile and compressive behavior are characterized by damaged plasticity.

The CDP model is a modification of the DruckerPrager strength hypothesis. In recent years, the latter has been further modified by Lubliner et al. [15], and Lee and Fenves [16]. According to the modifications, the failure surface in the deviatory cross-section needs not to be a circle, and it is governed by parameter $K_{C}$ [17]. Physically, parameter $K_{C}$ is interpreted as the 
ratio of the distances between the hydrostatic axis and respectively the compression meridian and the tension meridian in the deviatory cross-section. This ratio is always higher than 0.5 , and when it assumes the value of 1 , the deviatory cross-section of the failure surface becomes a circle (as in the classic Drucker-Prager strength hypothesis). The CDP model recommends to assume $K_{C}=2 / 3$.

In the CDP model, the plastic potential surface in the meridional plane assumes the form of a hyperbola. The shape is adjusted through eccentricity (plastic potential eccentricity). It is a small positive value which expresses the rate of approach of the plastic potential hyperbola to its asymptote.

In the CDP model, the plastic potential surface in the meridional plane assumes the form of a hyperbola. The shape is adjusted through eccentricity (plastic potential eccentricity). It is a small positive value which expresses the rate of approach of the plastic potential hyperbola to its asymptote. In other words, it is the length (measured along the hydrostatic axis) of the segment between the vertex of the hyperbola and the intersection of the asymptotes of this hyperbola (the center of the hyperbola). Parameter eccentricity can be calculated as a ratio of tensile strength to compressive strength [18]. The CDP model recommends to assume $\varepsilon=0.1$. When $\varepsilon=0$, the surface in the meridional plane becomes a straight line (the classic DruckerPrager hypothesis).

Another parameter describing the state of the material is the point in which the concrete undergoes failure under biaxial compression. $\sigma_{b 0} / \sigma_{c 0}\left(f_{b 0} / f_{c 0}\right)$ is a ratio of the strength in the biaxial state to the strength in the uniaxial state. The ABAQUS user's manual specifies default $\sigma_{b 0} / \sigma_{c o}=1.16$.

The last parameter characterizing the performance of concrete under compound stress is dilation angle, i.e. the angle of inclination of the failure surface towards the hydrostatic axis, measured in the meridional plane. Physically, dilation angle, $\psi$, is interpreted as a concrete internal friction angle. In simulations, usually $\psi=36^{\circ}$ or $\psi=40^{\circ}$ is assumed.

For modeling steel reinforcing steel, an elastoplastic model is used to determine the behavior of steel in tension and compression. Full bond between steel and concrete is assumed.

For modeling the FRP, it is considered as a linear elastic material until failure and the interaction between the concrete and the FRP is modeled without considering debonding. To check debonding, FRP strains are controlled during analysis and the effective strain at failure is evaluated by ACI 440 [19].

\section{Control model for verifying}

In order to confirm the applicability of the proposed

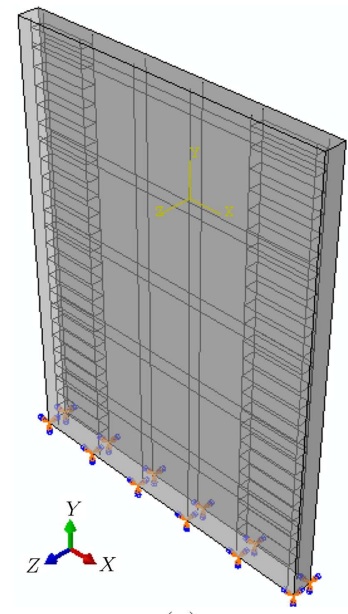

(a)

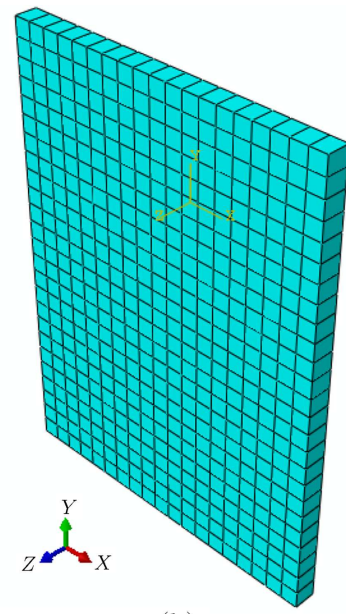

(b)
Figure 2. FE Models of the wall: (a) Boundary condition, (b) mesh pattern.

numerical models used in this study, experimental results from one of the $\mathrm{RC}$ shear walls tested by Lombard et al. [6] are used. Two walls were modeled: a control wall and a strengthened wall with one vertical layer of carbon fiber sheets applied to each side of the wall. In Figure 2, boundary conditions and mesh of the finite-element model of the walls are shown. The walls are constructed using $40 \mathrm{MPa}$ concrete with identical reinforcement of $400 \mathrm{MPa}, 10 \mathrm{~mm}$ reinforcing steel bars. The height of the wall panel to the cap beam is $2000 \mathrm{~mm}$, and the length is $1500 \mathrm{~mm}$ and the thickness is $100 \mathrm{~mm}$. The vertical reinforcement consists of six pairs of $10 \mathrm{~mm}$ reinforcing bars, providing a reinforcement ratio of $0.8 \%$. The horizontal reinforcement consists of five pairs of $10 \mathrm{~mm}$ reinforcing bars, providing a reinforcement ratio of $0.5 \%$.

For the control wall, the ultimate load is determined to be $178 \mathrm{kN}$ and the ultimate load $258 \mathrm{kN}$ for the strengthened wall, which corresponded to a $46 \%$ increase in the ultimate load-carrying capacity of the strengthened wall [6].

The validity of the proposed material models for steel, concrete, and FRP was verified by testing against experimental data. The results of the verification study in Figures 3 and 4 demonstrate that the numerical model fit with the acceptable accuracy of the experimental results of the reference walls. In both walls, the numerical predictions for lateral load and corresponding displacement are larger than the measured data from experimental test, but the error percentage is less than $4 \%$.

\section{Models characteristics}

After ensuring the accuracy of the results of the analysis in ABAQUS, analytical samples were defined and modeled. A wall is designed according to ACI 318-08 [20]. As shown in Figure 5, the wall has a 


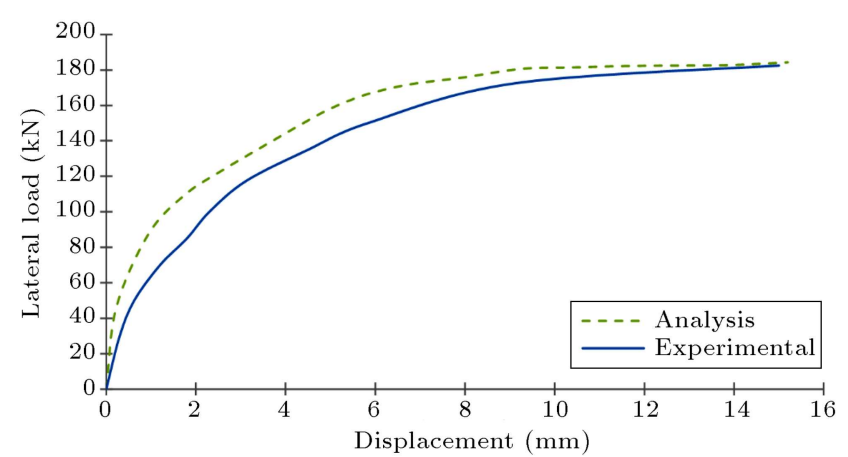

Figure 3. Load-displacement curve from experimental and numerical analyses of control wall.

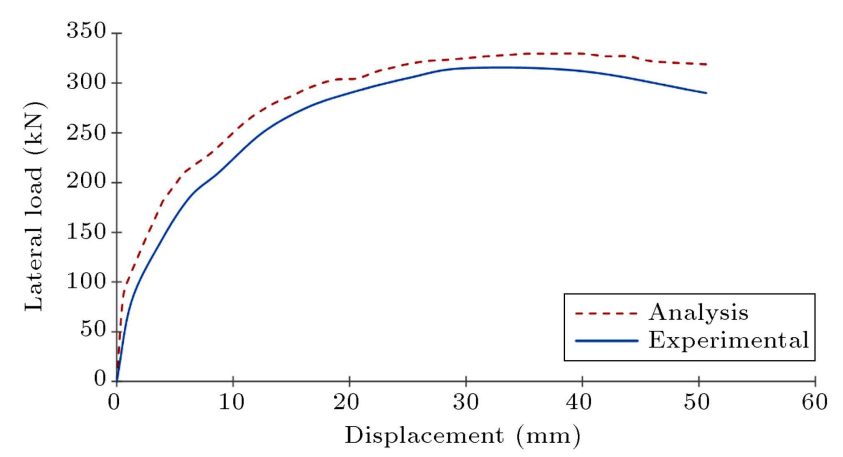

Figure 4. Load-displacement curve from experimental and numerical analyses of strengthened wall.
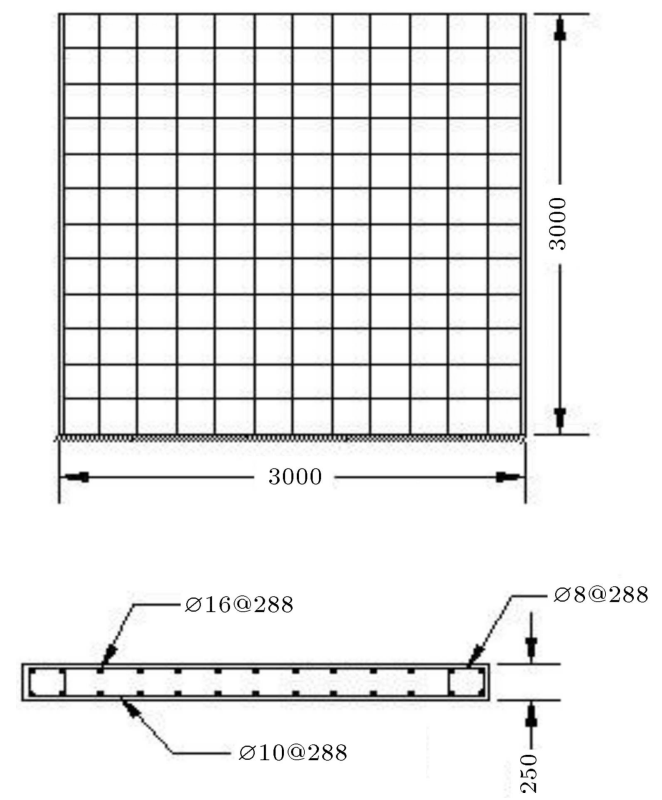

Figure 5. Wall panel specimen and its reinforcement.

rectangular section with the overall height of $3 \mathrm{~m}$, length of $3 \mathrm{~m}$, and a thickness of $25 \mathrm{~mm}$. The architectural plan of the building is shown in Figure 6. The boundary condition at the base of the wall is simulated as fixed end. The compressive strength of concrete and the yield stress of reinforcement bars are $40 \mathrm{MPa}$ and $400 \mathrm{MPa}$, respectively. CFRP sheets are used for the

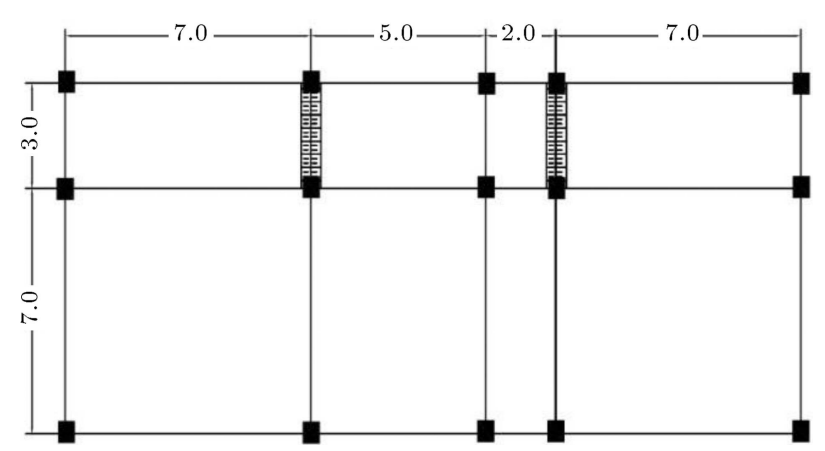

Figure 6. Plan of the purposed building.

purpose of strengthening the characteristics according to Table 1 . In this study, displacement-control method is adopted for loading by applying displacement to the top of the wall. To reach the target displacement, which is $2 \%$ of the total structure height according to UBC1997, loading rate should be in a way that displacement reaches $2 \%$ in drift.

To study the effect of different FRP strengthening schemes on the wall's behavior, eight different schemes are designed and modeled. Details of these schemes are as follows:

- Full coverage of wall surface with vertical oriented fibers (SSW1);

- Full coverage of wall surface with horizontal oriented fibers (SSW2);

- Full coverage of wall surface with a vertical layer and a horizontal layer (SSW3);

- Full coverage of wall surface with a horizontal layer along with vertical strips in boundary elements (SSW4);

- Full coverage of wall surface with fiber orientation.

The strengthening schemes of SSW5, SSW7, and SSW8, in which FRP strips are used, are shown in Figure 7. Modeling is done for $0.2 \mathrm{~mm}$ and $0.8 \mathrm{~mm}$ thickness shown by $\mathrm{T} 1$ and $\mathrm{T} 2$, respectively.

In order to study the effect of the opening on the wall behavior, several walls with openings of different dimensions and locations are modeled. Various schemes for strengthening these walls are presented.

In general, two groups of walls are modeled. These walls are similar to the Control Wall. The first

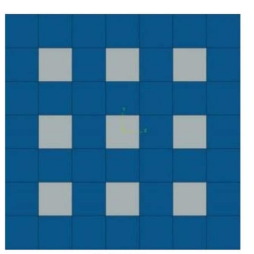

SSW5

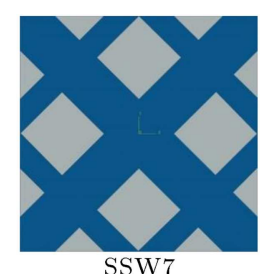

SSW7

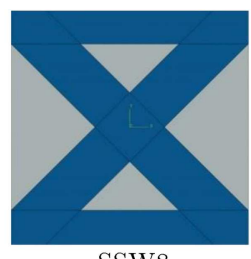

SSW8
Figure 7. Strengthening schemes of SSW5, SSW7, and SSW8. 
Table 1. Mechanical properties of CFRP composite used in the FRP strengthening.

\begin{tabular}{|c|c|c|c|c|c|}
\hline Parameter & $\begin{array}{c}\text { Elasticity } \\
\text { modulus } \\
(\text { GPa })\end{array}$ & $\begin{array}{l}\text { Poisson's } \\
\text { ratio }\end{array}$ & $\begin{array}{c}\text { Tensile } \\
\text { modulus (GPa) }\end{array}$ & $\begin{array}{c}\text { Tensile } \\
\text { strength (MPa) }\end{array}$ & $\begin{array}{c}\text { Laminate } \\
\text { thickness }(\mathrm{mm})\end{array}$ \\
\hline Value & $\left\{\begin{array}{l}E_{x}=169 \\
E_{y}=13 \\
E_{z}=13\end{array}\right.$ & $\left\{\begin{array}{l}v_{x y}=0.22 \\
v_{y z}=0.3 \\
v_{z x}=0.22\end{array}\right.$ & $\left\{\begin{array}{l}G_{x y}=8 \\
G_{y z}=4.7 \\
G_{z x}=8\end{array}\right.$ & $F_{u}=1000$ & 0.2 \\
\hline
\end{tabular}

Table 2. Location of wall openings.

\begin{tabular}{ccc} 
Wall & $\begin{array}{c}\text { Location } \\
\text { of opening }\end{array}$ & $\begin{array}{c}\text { The ratio of opening } \\
\text { area to wall area }\end{array}$ \\
\hline CO.CSW & & 0.33 \\
LO.CSW & $\rightarrow$ & 0.33 \\
RO.CSW & $\rightarrow$ & 0.11 \\
MO.CSW & & \\
\hline
\end{tabular}

group has a door opening of $1.5 \times 2 \mathrm{~m}$ whose location changes through the wall length. The second group has a window opening of $1 \times 1 \mathrm{~m}$ whose location changes through the wall height. The openings' locations are shown in Table 2.

The strengthening schemes are based on walls cracking patterns and their weak points. FRP schemes consist of FRP wraps around the openings with fibers oriented perpendicular to the cracks and FRP wraps with fibers oriented horizontally for the top and bottom areas of the opening width of $0.5 \mathrm{~m}$.

Control wall load-displacement response is shown in Figure 8. Also, cracking displacement and load,

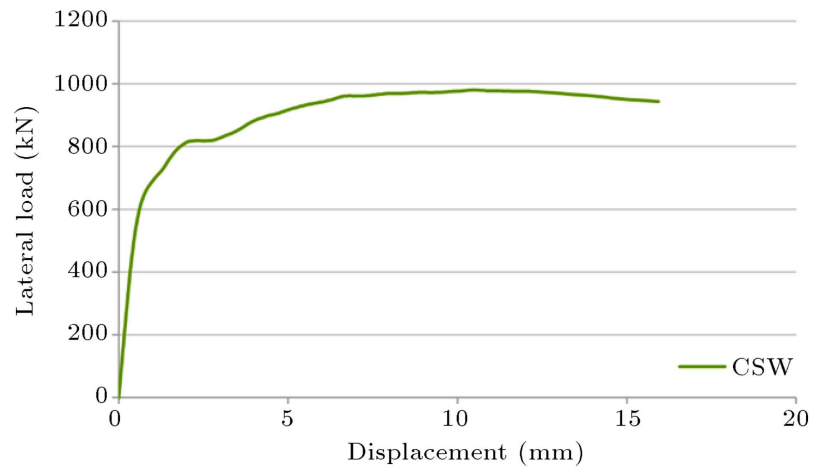

Figure 8. Load-displacement curve for control wall (CSW).

ultimate displacement and load, ductility and control wall's absorbed energy are shown in Table 3.

\section{Analysis results}

\subsection{Idealization}

In order to perform a study on the results, it is necessary to assume an elastic-plastic idealization of the load-displacement $(V-\Delta)$ behavior. This bilinear diagram is defined in terms of two characteristic points: (a) The effective yielding displacement $(y)$ which denotes the change between elastic and plastic behaviors, and (b) the ultimate displacement $(u)$.

The idealized diagrams are obtained from analytical diagrams using method of MBBE; in this method, the idealization is performed through an energy balance (Figure 9) between the analytical curve and the ideal diagram. That is the area below the analytical curve (OCD in Figure 9) which is equal to the area below the ideal elastic-plastic curve (OBCD). The effective yielding deformation is obtained by matching areas $A_{1}$ to $A_{2}$. This method is termed "Method Based on Balanced Energy (MBBE)" [21].

Table 3. Control Shear Wall (CSW) results.

\begin{tabular}{|c|c|c|c|c|c|c|c|}
\hline Specimen & $\begin{array}{c}\text { Cracking } \\
\text { load } \\
(\mathrm{kN}) \\
\left(P_{c r}\right) \\
\end{array}$ & $\begin{array}{c}\text { Ultimate } \\
\text { load } \\
(\mathrm{kN}) \\
\left(P_{u}\right) \\
\end{array}$ & $\begin{array}{c}\text { Cracking } \\
\text { displacement } \\
(\mathrm{mm}) \\
\left(\Delta_{c r}\right) \\
\end{array}$ & $\begin{array}{c}\text { Ultimate } \\
\text { displacement } \\
(\mathbf{m m}) \\
\left(\Delta_{u}\right) \\
\end{array}$ & $\begin{array}{c}\text { Yield } \\
\text { displacement } \\
(\mathbf{m m}) \\
\left(\Delta_{y}\right) \\
\end{array}$ & $\begin{array}{l}\text { Ductility } \\
\qquad(\mu)\end{array}$ & $\begin{array}{c}\text { Energy absorption } \\
\qquad(\mathrm{kN} . \mathrm{mm})\end{array}$ \\
\hline CSW & 494 & 980 & 0.44 & 16 & 2.4 & 6.67 & 14315 \\
\hline
\end{tabular}




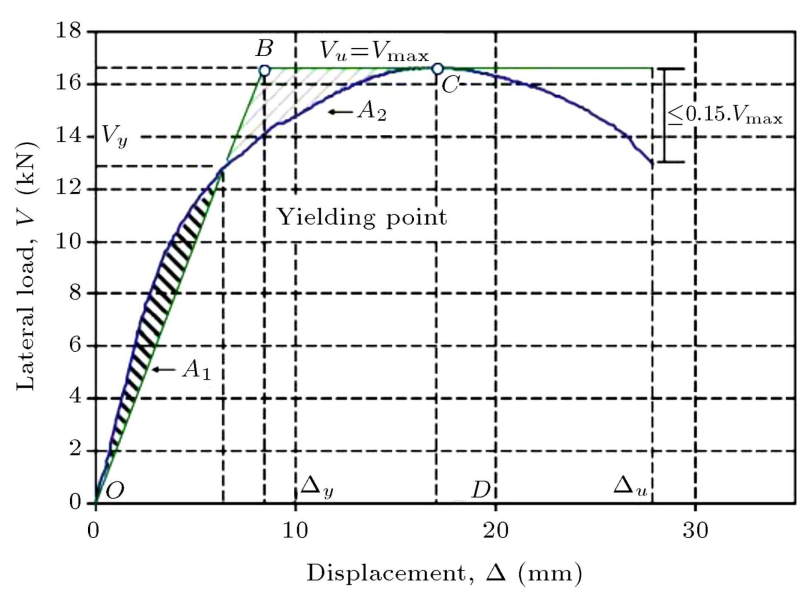

Figure 9. Definition of ultimate and ideal yield displacement [21].

\subsection{Ultimate displacement}

This factor is defined when a reduction factor of $15 \%$ of the maximum load is reached in the descending branch [22]. In the models in which a long descending branch corresponding to a $15 \%$ reduction is not obtained, the last measurement is selected as the ultimate displacement $(\Delta u)$.

\subsection{Yielding displacement}

The yielding displacement is obtained through the intersection between the elastic and plastic branches which denotes the change between elastic and plastic behaviors on the idealized diagram.

\subsection{Ductility factor}

The ductility factor is obtained from the proportion of ultimate displacement to the yielding displacement. This concept shows the ability of the structure to endure the linear state:

$$
\mu=\frac{\Delta u}{\Delta y} .
$$

\subsection{Response modification factor}

Response modification factors are calculated based on derived results of pushover analysis. These factors are then compared. $R$ factors are derived from Eq. (1).

\subsection{Energy absorption}

This term is used for the dissipated energy within the wall which is calculated as the area under $(V-\Delta)$ curve.

In this section, the results are presented and discussed in the form of graphs and tables. The load-displacement response of walls is presented in Figures 10 and 11.

\section{Discussion}

According to Table 4, seven out of sixteen strengthened walls have more ductility than CSW wall. The maximum ductility belongs to SSW5, SSW7, and SSW8 walls. It can be concluded that in these walls, due to weakness in shear and ductility, the foremost ductility can be achieved when the overall area of the wall is not

Table 4. Numerical results of 16 strengthened solid walls.

\begin{tabular}{|c|c|c|c|c|c|c|c|c|c|c|}
\hline Specimen & $\begin{array}{c}P_{c r} \\
(\mathbf{k N})\end{array}$ & $\begin{array}{c}\text { Ultimate } \\
\text { load, } P_{u} \\
(\mathrm{kN}) \\
\end{array}$ & $\begin{array}{c}\Delta_{c r} \\
(\mathrm{~mm})\end{array}$ & $\begin{array}{c}\text { Ultimate } \\
\text { disp. }^{a}\end{array}$ & $\begin{array}{c}\text { Yield } \\
\text { disp., } \Delta_{y} \\
(\mathrm{~mm}) \\
\end{array}$ & Ductility, $\mu$ & $\begin{array}{c}\text { Energy } \\
\text { absorption } \\
(\mathrm{kN} . \mathrm{mm}) \\
\end{array}$ & $\boldsymbol{R}_{\mu}$ & $R_{\Omega}$ & $\boldsymbol{R}=\boldsymbol{R}_{\mu} \times \boldsymbol{R}_{\Omega}$ \\
\hline CSW & 494 & 980.2 & 0.44 & 16 & 2.4 & 6.67 & 14315 & 3.51 & 1.98 & 4.96 \\
\hline SSW1-T1 & 504.7 & 1200 & 0.45 & 20 & 4.1 & 4.88 & 22461 & 2.96 & 2.38 & 5.03 \\
\hline SSW1-T2 & 507.9 & 1290 & 0.45 & 18 & 4.4 & 4.09 & 20210 & 2.68 & 2.54 & 4.86 \\
\hline SSW2-T1 & 526.6 & 1020 & 0.48 & 21 & 2.9 & 7.24 & 20345 & 3.67 & 1.94 & 5.09 \\
\hline SSW2-T2 & 527.2 & 1060 & 0.48 & 26 & 3.6 & 7.22 & 24902 & 3.67 & 2.01 & 5.27 \\
\hline SSW3-T1 & 538.2 & 1280 & 0.49 & 25.8 & 5.1 & 5.06 & 29150 & 3.02 & 2.38 & 5.14 \\
\hline SSW3-T2 & 542.6 & 1500 & 0.49 & 29.2 & 7.5 & 3.89 & 37753 & 2.6 & 2.76 & 5.13 \\
\hline SSW4-T1 & 522.1 & 1200 & 0.48 & 21 & 4.6 & 4.57 & 22195 & 2.85 & 2.3 & 4.69 \\
\hline SSW4-T2 & 540.4 & 1360 & 0.49 & 25 & 6.2 & 4.03 & 29562 & 2.66 & 2.52 & 4.79 \\
\hline SSW5-T1 & 518.6 & 1120 & 0.48 & 33 & 3.9 & 8.46 & 33983 & 3.99 & 2.16 & 6.16 \\
\hline SSW5-T2 & 521.4 & 1130 & 0.48 & 36 & 5.1 & 7.06 & 40343 & 3.62 & 2.17 & 5.61 \\
\hline SSW6-T1 & 538.2 & 1370 & 0.49 & 32.4 & 7.9 & 4.1 & 38376 & 2.68 & 2.55 & 4.88 \\
\hline SSW6-T2 & 547.5 & 1680 & 0.5 & 50 & 12 & 4.17 & 73388 & 2.71 & 3.07 & 5.94 \\
\hline SSW7-T1 & 540.6 & 1200 & 0.5 & 39 & 5.3 & 7.36 & 40174 & 3.7 & 2.22 & 5.86 \\
\hline SSW7-T2 & 536.8 & 1360 & 0.5 & 47 & 7.5 & 6.27 & 58169 & 3.4 & 2.53 & 6.14 \\
\hline SSW8-T1 & 508.1 & 1080 & 0.46 & 25.7 & 6 & 4.28 & 25507 & 2.75 & 2.13 & 4.19 \\
\hline SSW8-T2 & 514.5 & 1190 & 0.47 & 40 & 6 & 6.67 & 43744 & 3.51 & 2.31 & 5.79 \\
\hline
\end{tabular}



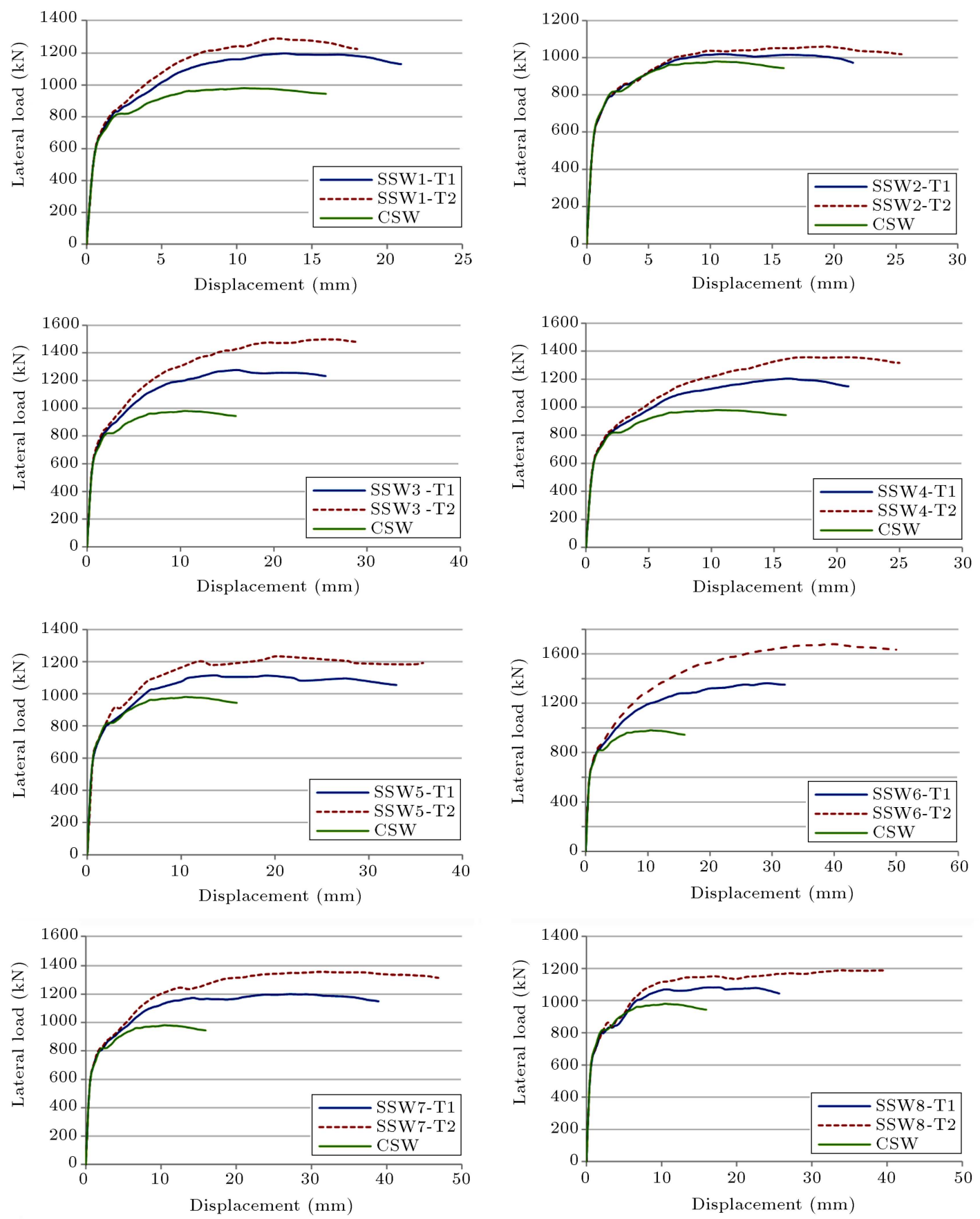

Figure 10. Load-displacement curve of 16 strengthened solid walls.

covered with FRP, but there has been an increase in shear strength of the wall.

In general, increasing FRP thickness has resulted in a decrease in ductility, although the shear strength has increased. Only SSW8 showed an increase in ductility by using thicker FRP laminate which has resulted in a confinement increase in wall base that has caused failure above the horizontal strip.

Openings in walls have caused a great decrease in their ductility. Walls with opening area of $11 \%$ showed a greater ductility compared to those with the opening area of $33 \%$ of the wall area. The opening location is also an effective factor in ductility. The maximum ductility belongs to MO.CSW and the minimum amount refers to RO.SSW.

The maximum absorbed energy is related to SSW6-T2, SSW7-T2, and SSW8-T2 walls. Thickness increase has an effective role in energy absorption. The maximum effect of this factor can be observed in SSW6 wall which has had a $91 \%$ increase in its energy absorption due to the increase in FRP thickness.

Excluding CO.CSW, BO.CSW, and LO.CSW, in 

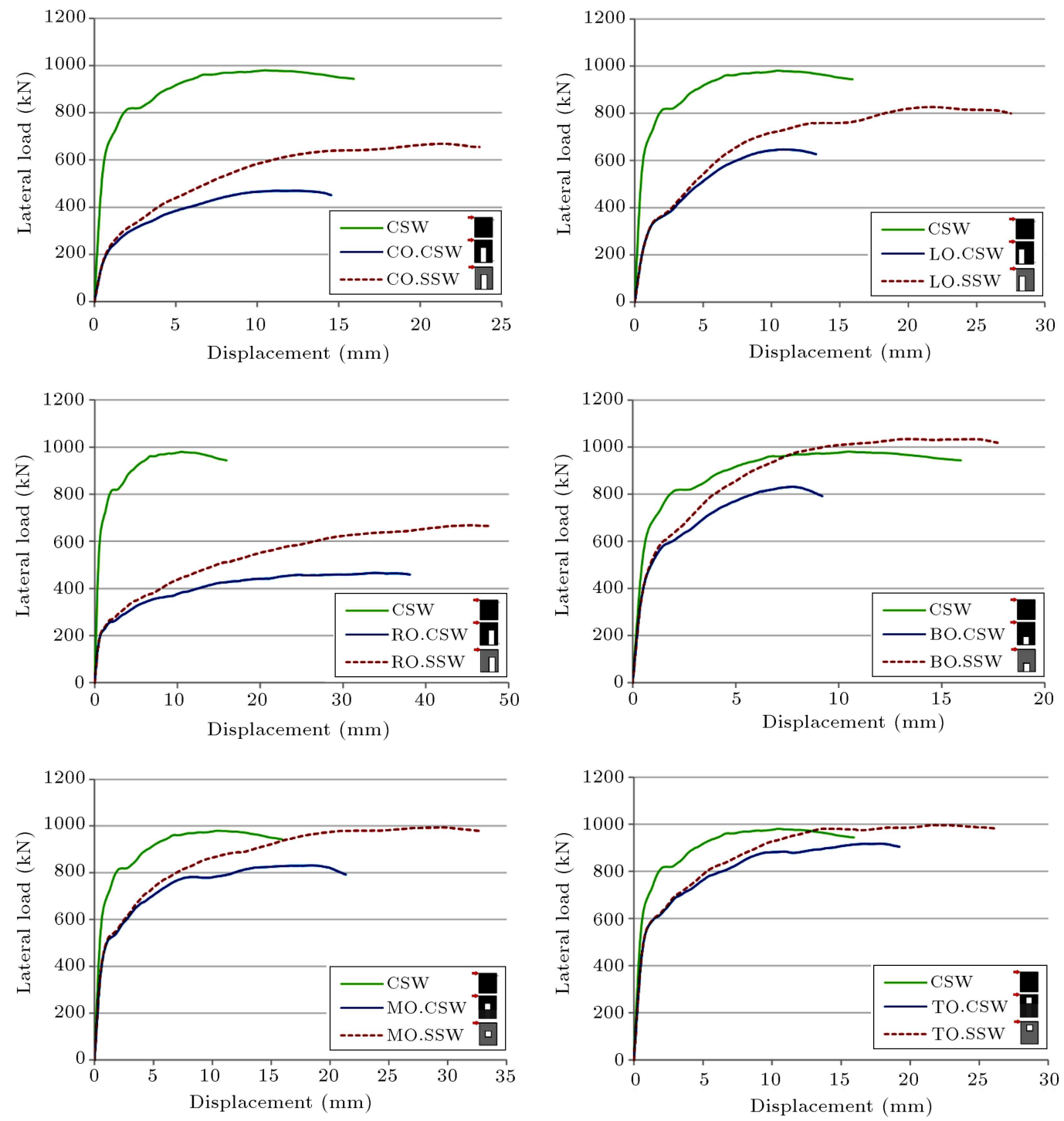

Figure 11. Load-displacement curve of 16 strengthened walls with openings.

all other walls, the amount of absorbed energy is more than CSW. Wall strengthening has increased its energy absorption significantly.

Using the results and considering the nonlinear behavior of threshold corresponding forces and walls ultimate strength, overstrength of the understudy walls is calculated. This quantity, along with the decreasing factor due to ductility, is calculated using Newmark and Hall, 1982 [13]. Also, behavior factor which is consisted of these two parameters is represented in Tables 4 and 5. To apply the exploitation level, 1.4 factor related to seismic loading combinations is taken into account according to ACI-318 code when calculating the behavior factor. The reason for this application is that walls are loaded until the fracture moment and the analytical results correspond to seismic forces of strength level.

It is observed that the overstrength factor ranges from 1.94 to 5.64 related to SSW2-T2 and CO.SSW, respectively. In general, this factor has increased in all applied patterns when the FRP thickness is stepped up. Walls with openings have had greater overstrength factor in comparison to those without openings. Among diverse strengthening patterns of CSW wall, those with supplied sufficient shear strength for the wall have had further overstrength factors. An example of this is SSW6 wall.

Decreasing factor due to ductility varies from 2.06 to 3.99 which belongs to LO.CSW and SSW5-T1, respectively.

Walls' behavior factor ranges from 4.19 to 8.58 in which the maximum amount belongs to SSW5-T1 and the minimum one is related to SSW8-T1.

\section{Conclusion}

In this research, to strengthen the shear walls by FRP composite laminates, eight different strengthening 
Table 5. Numerical results of 16 strengthened walls with openings.

\begin{tabular}{|c|c|c|c|c|c|c|c|c|c|c|}
\hline Specimen & $\begin{array}{c}P_{c r} \\
(k N)\end{array}$ & $\begin{array}{c}\text { Ultimate } \\
\text { load, } P_{u} \\
(\mathrm{kN})\end{array}$ & $\begin{array}{c}\Delta_{c r} \\
(\mathrm{~mm})\end{array}$ & $\begin{array}{l}\text { Ultimate } \\
\text { disp. }^{a}\end{array}$ & $\begin{array}{c}\text { Yield } \\
\text { disp., } \Delta_{y} \\
(\mathrm{~mm}) \\
\end{array}$ & Ductility, $\mu$ & $\begin{array}{c}\text { Energy } \\
\text { absorption } \\
(\mathrm{kN} . \mathrm{mm})\end{array}$ & $\boldsymbol{R}_{\mu}$ & $R_{\Omega}$ & $\boldsymbol{R}=\boldsymbol{R}_{\mu} \times \boldsymbol{R}_{\Omega}$ \\
\hline CO.CSW & 104.6 & 470.4 & 0.3 & 14.5 & 4.57 & 3.18 & 5702 & 2.32 & 4.5 & 7.46 \\
\hline CO.SSW & 118.5 & 668.1 & 0.33 & 23 & 8.32 & 2.76 & 12891 & 2.13 & 5.64 & 8.58 \\
\hline LO.CSW & 149.9 & 645.7 & 0.38 & 13.3 & 5.04 & 2.63 & 6878 & 2.06 & 4.31 & 6.34 \\
\hline LO.SSW & 161.2 & 825.8 & 0.4 & 27.5 & 8.76 & 3.14 & 18914 & 2.3 & 5.12 & 8.41 \\
\hline RO.CSW & 121.2 & 466.4 & 0.3 & 38.1 & 9.27 & 4.11 & 15488 & 2.69 & 3.85 & 7.4 \\
\hline RO.SSW & 132.2 & 668.5 & 0.33 & 47.5 & 17.9 & 2.66 & 25576 & 2.08 & 5.06 & 7.51 \\
\hline BO.CSW & 283.4 & 831 & 0.3 & 9.19 & 2.87 & 3.2 & 6409 & 2.32 & 2.93 & 4.86 \\
\hline BO.SSW & 330 & 1034.4 & 0.38 & 17.69 & 4.44 & 3.98 & 15875 & 2.64 & 3.13 & 5.9 \\
\hline MO.CSW & 331.4 & 831.2 & 0.39 & 21.3 & 4.21 & 5.07 & 15826 & 3.02 & 2.51 & 5.41 \\
\hline MO.SSW & 335.4 & 994.4 & 0.41 & 32.6 & 7.37 & 4.34 & 28577 & 2.8 & 2.96 & 5.92 \\
\hline TO.CSW & 314.7 & 917.7 & 0.38 & 19.2 & 4.35 & 4.42 & 15502 & 2.8 & 2.92 & 5.84 \\
\hline TO.SSW & 343 & 995.3 & 0.4 & 26.1 & 5.28 & 4.94 & 23120 & 2.98 & 2.9 & 6.17 \\
\hline
\end{tabular}

a disp.: displacement.

schemes were presented. These walls were analyzed by a nonlinear static method whose derived results are as follows:

- All the strengthening schemes have enhanced the ultimate capacity of the wall. Admittedly, SSW6-T2 by $70 \%$ increase and SSW2-T1 by $4 \%$ decrease have maximum and minimum effective strengthening, respectively;

- Walls' ductility ranges from 3.89 to 8.46 . In general, although increasing FRP thickness has increased shear strength, it has decreased ductility as well which varies depending on the strengthening scheme;

- Using FRP laminates, the absorbed energy has remarkably increased. This amount varies from 1.4 to 5.1 times of CSW energy absorption which belongs to SSW1-T1 and SSW6-T2, respectively. Thickness increase affects the energy absorption. The maximum effectiveness correspond to SSW6 in which the absorbed energy has increased by $91 \%$ by increasing thickness;

- Behavior factor varies from 4.19 to 6.16. The maximum factor belongs to SSW5-T1, whereas the minimum one is related to SSW8-T1.

Also, in this research, the effect of opening, both its size and location on wall behavior, is investigated and the results are as follows:

- In walls with openings of $11 \%$ area of the wall, capacity decreased by $15 \%$. Changing the opening location in the wall height caused significant effect on the wall behavior, since it changes the load path. Admittedly, when the opening is located at the base of the wall, the minimum capacity, ductility, energy absorption, and behavior factor occur. After strengthening these walls, capacity has increased by at least $24 \%$. Also, energy absorption and behavior factor have increased by at most $148 \%$ and $10 \%$, respectively;

- In walls with openings of $33 \%$ area of the wall, capacity decreased by $52 \%$. Changing the opening location in the wall length did not cause significant effect on the wall behavior where the main reason for this is that the function of the wall changes to frame action. Ductility and energy absorption have decreased in these walls, whereas behavior factor has increased by at least $30 \%$ in comparison to control wall due to their high overstrength. After strengthening these walls, ductility has decreased by $35 \%$, whereas behavior factor and energy absorption have increased by $33 \%$ and $178 \%$, respectively.

\section{References}

1. Fiorato, A., Oesterle, R. and Corley, W. "Behavior of earthquake resistant structural walls before and after repair", J. Am. Concr. Inst., 80(5), pp. 403-413 (1983).

2. Taghdi, M., Bruneau, M. and Saatcioglu, M. "Seismic retrofitting of low-rise masonry and concrete walls using steel strips", J. Struct. Eng., 126(9), pp. 10171025 (2000). 
3. Bakis, C.E., Lawrence, C.B., Brown, V.L. and Cosenza, E. "Fiber-reinforced polymer composites for construction-state-of-the-art review", J. Compos. Constr., 6(2), pp. 73-87 (2002).

4. Vecchio, F., Haro de la Pena, O., Bucci, F. and Palermo, D. "Behavior of repaired cyclically loaded shear walls", ACI Struct. J., 99(3), pp. 27-334 (2002).

5. Effendy, E., Liao, W., Song, G., Mo, Y. and Loh, C. "Seismic behavior of low-rise shear walls with SMA bars", Proc., 10th Biennial Int. Conf. on Engineering, Construction, and Operations in Challenging Environments, Earth and Space, ASCE, Reston, VA (2006).

6. Lombard, J., Lau, D.T., Humar, J.L., Foo, S. and Cheung, M.S. "Seismic strengthening and repair of concrete shear walls", Proceeding of 12th WCEE Conference, New Zealand (2000).

7. Antoniades, K., Salonikios, T. and Kappos, A. "Cyclic tests on seismically damaged reinforced concrete walls strengthened using fiber-reinforced polymer reinforcement", ACI Struct. J., 100(4), pp. 510-518 (2003).

8. Khalil, A. and Ghobarah, A. "Behavior of rehabilitated structural walls", J. Earthquake Eng., 9(3), pp. 371391 (2005).

9. El-Sokkary, H., Galal, K., Ghorbanirenani, I. and Leger, P. "Shake table tests on FRP-rehabilitated RC shear walls", Journal of Composites for Construction, 17(1), pp. 79-90 (2013).

10. El-Sokkary, H. and Galal, K. "Seismic behavior of RC shear walls strengthened with fiber-reinforced polymer", Journal of Composites for Construction, 17(5), pp. 603-613 (2013).

11. Li, B., Kai, Q. and Cao, T. "Retrofitting earthquakedamaged RC structural walls with openings by externally bonded FRP strips and sheets", Journal of Composites for Construction, ASCE, pp. 259-270 (2013).

12. Newmark, N.M. and Hall, W.J. "Seismic design criteria for nuclear reactor facilities", Proceedings of the 4 th World Conference on Earthquake Engineering, Santiago, Chile B-4, pp. 37-50 (1969).

13. Newmark, N.M. and Hall, W.J. "Earthquake spectra and design", Engineering Monograph Earthquake Engineering Research Institute, Berkeley, California (1982).

14. ABAQUS theory manual and user's manual, version 6.13 (2013).

15. Lubliner, J., Oliver, J., Oller, S. and Oñate, E. "A plastic-damage model for concrete", International Journal of Solids and Structures, 25, pp. 299-329 (1989).
16. Lee, J. and Fenves, G.L. "Plastic-damage model for cyclic loading of concrete structures", Journal of Engineering Mechanics, 124(8), pp. 892-900 (1998).

17. Kmiecik, P. and Kaminski, M. "Modelling of reinforced concrete structures and composite structures with concrete strength degradation taken into consideration", Archives of Civil and Mechanical Engineering, 11(3), pp. 623-636 (2011).

18. Jankowiak, I., Kakol, W. and Madaj, A. "Identification of a continuous composite beam numerical model based on experimental tests", 7th Conference on Composite Structures, Zielona Góra, pp. 163-178 (2005).

19. ACI Committee 440, Guide for the Design and Construction of Externally Bonded FRP Systems for Strengthening Concrete Structures, ACI 440.2R-08, American Concrete Institute, Farmington Hills, MI (2008).

20. ACI 318-08, Building Code Requirements for Structural Concrete and Commentary - ACI 318-08, American Concrete Institute, Farmington Hills, MI, USA (2008).

21. Lam, S.S.E., Wu, B., Wong, Y.L., Wang, Z.Y., Liu, Z.Q. and Li, C.S. "Drift capacity of rectangular reinforced concrete columns with low lateral confinement and high-axial load", J. Struct. Eng. - ASCE, 129(6), pp. 733-42 (2003).

22. Wang, T. and Hsu, T.T.C. "Nonlinear finite element analysis of concrete structures using new constitutive models", Computers and Structures, 79(32), pp. 27812791 (2001).

\section{Biographies}

Bahareh Mohammadi Vojdan was born in 1990 in Kermanshah. She received her BSc degree in Civil Engineering and MSc in Structural Engineering from Razi University of Kermanshah in 2012 and 2015, respectively.

Reza Aghayari was born in 1974 in Tehran, Iran. He received his BSc degree from Urmia University in 1996, his MSc from University of Tabriz in 1998, and his PhD degree from Tarbiat Modares University in 2009. He is currently an Associate Professor of Civil Engineering at Razi University of Kermanshah. His research interest mainly focuses on reinforced concrete structures. 